\title{
Development of capsular polysaccharide-based glycoconjugates for immunization against melioidosis and glanders
}

\author{
Mary N. Burtnick ${ }^{1}$, Christian Heiss ${ }^{2}$, Rosemary A. Roberts ${ }^{1}$, Herbert P. Schweizer ${ }^{3}$, Parastoo Azadi ${ }^{2}$ \\ and Paul J. Brett ${ }^{1 *}$
}

1 Department of Microbiology and Immunology, University of South Alabama, Mobile, AL, USA

${ }^{2}$ Complex Carbohydrate Research Center, The University of Georgia, Athens, GA, USA

${ }^{3}$ Department of Microbiology, Immunology and Pathology, Colorado State University, Fort Collins, CO, USA

\section{Edited by:}

Mark Estes, University of Georgia, USA

\section{Reviewed by:}

Joanna Goldberg, University of Virginia Health System, USA

Omar Qazi, The University of Texas at Austin, USA

${ }^{*}$ Correspondence:

Paul J. Brett, Department of Microbiology and Immunology, University of South Alabama, 5851 USA Drive North, Mobile, AL 36688, USA.

e-mail:pbrett@southalabama.edu
Burkholderia pseudomallei and Burkholderia mallei, the etiologic agents of melioidosis and glanders, respectively, cause severe disease in humans and animals and are considered potential agents of biological warfare and terrorism. Diagnosis and treatment of infections caused by these pathogens can be challenging and, in the absence of chemotherapeutic intervention, acute disease is frequently fatal. At present, there are no human or veterinary vaccines available for immunization against these emerging/re-emerging infectious diseases. One of the long term objectives of our research, therefore, is to identify and characterize protective antigens expressed by B. pseudomallei and B. mallei and use them to develop efficacious vaccine candidates. Previous studies have demonstrated that the 6-deoxy-heptan capsular polysaccharide (CPS) expressed by these bacterial pathogens is both a virulence determinant and a protective antigen. Consequently, this carbohydrate moiety has become an important component of the various subunit vaccines that we are currently developing in our laboratory. In the present study, we describe a reliable method for isolating CPS antigens from O-polysaccharide (OPS) deficient strains of $B$. pseudomallei; including a derivative of the select agent excluded strain Bp82. Utilizing these purified CPS samples, we also describe a simple procedure for covalently linking these T-cell independent antigens to carrier proteins. In addition, we demonstrate that high titer IgG responses can be raised against the CPS component of such constructs. Collectively, these approaches provide a tangible starting point for the development of novel CPS-based glycoconjugates for immunization against melioidosis and glanders.

Keywords: Burkholderia pseudomallei, Burkholderia mallei, capsular polysaccharide, glycoconjugate, vaccine, immunization

\section{INTRODUCTION}

Burkholderia pseudomallei and Burkholderia mallei, the causative agents of melioidosis and glanders, respectively, are both CDC category B select agents (Howe and Miller, 1947; Redfearn et al., 1966; Yabuuchi et al., 1992). These facultative intracellular, Gramnegative pathogens are highly infectious via the respiratory route, and can cause severe, debilitating and often fatal diseases in humans and animals (Wiersinga et al., 2006; Whitlock et al., 2007; Galyov et al., 2010; Limmathurotsakul et al., 2012). The clinical symptoms of melioidosis and glanders tend to be multi-faceted and disease may manifest as chronic or acute localized infections, acute pulmonary infections, or fulminating septicemias. Treatment of these diseases can be challenging and even with appropriate chemotherapeutic intervention, mortality rates are unacceptably high (White, 2003; Khan et al., 2012; Meumann et al., 2012). At present, there are no human or veterinary vaccines available for immunization against melioidosis or glanders (Bondi and Goldberg, 2008; Sarkar-Tyson and Titball, 2010; Peacock et al., 2012).

Due to the potential misuse of B. pseudomallei and B. mallei as agents of biological warfare and terrorism, as well as their impact on public health in endemic regions, there has been a resurgence of interest in developing effective melioidosis and glanders vaccines (Rotz et al., 2002; Voskuhl et al., 2003; Peacock et al., 2012). To date, however, attempts to identify suitable candidates have been met with limited success. Recent studies indicate that vaccination of mice with lipopolysaccharide (LPS), capsular polysaccharide (CPS), non-viable (heat-killed/irradiated), or live-attenuated preparations of $B$. pseudomallei or B. mallei provide varying degrees of protection against a lethal challenge (Atkins et al., 2002; Nelson et al., 2004; Stevens et al., 2004; Ulrich et al., 2005; Whitlock et al., 2008; Sarkar-Tyson et al., 2009; 
Norris et al., 2011). Interestingly, whole cell preparations that fail to protect mice against challenge all appear to stimulate either mixed T-helper 1 (Th1)/T-helper 2 (Th2)-like or Th2-like biased cellular and humoral responses (Amemiya et al., 2002; Ulrich et al., 2005; Amemiya et al., 2006). In contrast, preparations affording protection appear to stimulate Th1-like biased cytokine (IL-2 and IFN- $\gamma$ ) and immunoglobulin responses (IgG2a $>\operatorname{IgG1}$ ) (Ulrich et al., 2005; Amemiya et al., 2006). Based upon these findings, immunity to melioidosis and glanders appears to be complex, requiring both humoral and cell-mediated responses. In addition, these studies suggest that whole cell or subunit based vaccine candidates promoting Th1-like responses will likely be required to immunize against disease caused by $B$. pseudomalle $i$ and B. mallei.

Capsular polysaccharides are a major component of Gramnegative cell envelopes. Structurally diverse in nature, these highly hydrated antigens exhibit a variety of important biological functions including resistance to desiccation, adherence to host tissues and protection against innate/acquired immune defenses (Bazaka et al., 2011). Curiously, B. pseudomallei and B. mallei isolates appear to be capable of expressing only a limited repertoire of structurally diverse CPS antigens. In fact, it has even been suggested that virulent clinical and/or environmental isolates of these pathogens can be defined by a single CPS serotype (Zou et al., 2008; Sim et al., 2010). At present, the significance of these observations with regard to virulence and evasion of host immune responses remains to be fully determined. Nevertheless, this attribute certainly bodes well from a vaccine development standpoint.

Previous studies have demonstrated that the predominant CPS antigen expressed by $B$. pseudomallei is an unbranched homopolymer consisting of monosaccharide repeats having the structure -3)-2-O-acetyl-6-deoxy- $\beta$-D-manno-heptopyranose(1- (6-deoxy-heptan; Perry et al., 1995). Although it has been recently shown that $B$. mallei also expresses an identical CPS antigen, studies indicate that for the most part, isolates of the closely related but non-pathogenic species, Burkholderia thailandensis, do not (Brett et al., 1998; DeShazer et al., 2001; Reckseidler et al., 2001). Based upon these observations, it has been proposed that the relative avirulence of $B$. thailandensis, in comparison to B. pseudomallei and B. mallei, may be due in part to the absence of this carbohydrate antigen (DeShazer et al., 2001; Reckseidler et al., 2001; Galyov et al., 2010).

Virulent isolates of B. pseudomallei and B. mallei, whether of human or veterinary origin, all appear to express the 6-deoxy-heptan CPS antigen (Zou et al., 2008). Importantly, previous studies by Reckseidler et al. (2001) have demonstrated that CPS-deficient mutants of B. pseudomallei are avirulent in a hamster model of infection. Similarly, studies by DeShazer et al. (2001) have also demonstrated that CPSdeficient mutants of $B$. mallei are avirulent in both murine and hamster models of infection. More recently, it has been shown that capsule production by $B$. pseudomallei contributes to resistance to phagocytosis by reducing $\mathrm{C} 3 \mathrm{~b}$ deposition on the surface of the bacterium, again implicating CPS as important virulence determinant (Reckseidler-Zenteno et al., 2005). Additionally, and germane to the present study, it has been shown that murine monoclonal antibodies (mAbs) specific for CPS are capable of passively immunizing mice against lethal challenges of B. pseudomallei and B. mallei (Jones et al., 2002; Zhang et al., 2011; AuCoin et al., 2012). Such findings confirm the protective capacity of this surface exposed antigen and support the rationale for exploring the use of CPS-based glycoconjugates as melioidosis and glanders vaccine candidates.

In this study, we describe the use of genetic, chemical, physi$\mathrm{cal}$, and immunological approaches to facilitate the development and preliminary testing of B. pseudomallei CPS-based glycoconjugates. It is anticipated that via the application of these approaches, we will gain valuable insights toward the rational design of glycoconjugate vaccines for immunization against diseases caused by B. pseudomallei and B. mallei.

\section{MATERIALS AND METHODS STRAINS AND GROWTH CONDITIONS}

The bacterial strains used in this study are described in Table $\mathbf{1 .}$ Unless otherwise stated, B. pseudomallei, B. mallei, and E. coli were grown at $37^{\circ} \mathrm{C}$ on Luria Bertani-Lennox (LBL) agar or in LBL broth. For B. pseudomallei Bp82 and its derivatives, growth media were supplemented with $100 \mu \mathrm{g} / \mathrm{ml}$ adenine hydrochloride (Sigma) and $5 \mu \mathrm{g} / \mathrm{ml}$ thiamine hydrochloride (Sigma). When appropriate, antibiotics were added at the following concentrations: $25 \mu \mathrm{g} / \mathrm{ml}$ kanamycin $(\mathrm{Km})$ or $15 \mu \mathrm{g} / \mathrm{ml}$ polymyxin B (Pm) for E. coli and $100 \mu \mathrm{g} / \mathrm{ml}$ (DD503) or $500 \mu \mathrm{g} / \mathrm{ml}$ (Bp82) $\mathrm{Km}$ for B. pseudomallei. Bacterial stocks were maintained at $-80^{\circ} \mathrm{C}$ as $20 \%$ glycerol suspensions. Other than B. pseudomallei Bp82 and its derivatives, all studies with $B$. pseudomallei and $B$. mallei were conducted in a CDC select agent certified biosafety level 3 containment facility.

\section{RECOMBINANT DNA TECHNIQUES}

The plasmids and oligonucleotide primers used in this study are described in Table 1. DNA manipulations were performed using standard methods. Restriction enzymes and T4 DNA Ligase (New England BioLabs) were used according to manufacturer's instructions. PCR was performed using an Expand High Fidelity PCR System (Roche Applied Science) or GoTaq DNA Polymerase (Promega); $1 \mathrm{M}$ Betaine (Sigma) was included in all PCR reactions. PCR was performed using the following conditions: $97^{\circ} \mathrm{C}$ for $5 \mathrm{~min}$; 30 cycles, each consisting of $97^{\circ} \mathrm{C}$ for $45 \mathrm{~s}, 55^{\circ} \mathrm{C}$ for $45 \mathrm{~s}$, and $72^{\circ} \mathrm{C}$ for $3 \mathrm{~min}$; a final extension step of $72^{\circ} \mathrm{C}$ for $10 \mathrm{~min}$ was included. PCR and restriction digested products were purified using a QIAquick Gel Extraction Kit (Qiagen). Plasmids were purified using a QIAprep Spin Miniprep Kit (Qiagen). Genomic DNA was purified using a Wizard Genomic DNA Purification kit (Promega). Chemically competent $E$. coli TOP10 cells were transformed as per the manufacturer's instructions (Invitrogen). Oligonucleotide primers were obtained from Integrated DNA Technologies (Coralville, IA).

\section{MUTANT CONSTRUCTION}

Gene replacement experiments with B. pseudomallei were conducted using the $s a c B$-based vector pMo130. To construct 
Table 1 | Strains, plasmids and primers.

\begin{tabular}{|c|c|c|}
\hline Strains & Relevant characteristics & Source or reference \\
\hline TOP10 & General cloning strain: $\mathrm{Km}^{\mathrm{s}}, \mathrm{Pm}^{\mathrm{s}}$ & Invitrogen \\
\hline \multicolumn{3}{|c|}{ B. pseudomallei ${ }^{\mathrm{a}}$} \\
\hline $1026 b$ & Clinical isolate & DeShazer et al., 1997 \\
\hline DD503 & 1026b derivative; $\Delta(a m r R$-amrAB-oprA $): \mathrm{Km}^{\mathrm{s}}, \mathrm{Pm}^{\mathrm{r}}$ & Moore et al., 1999 \\
\hline Bp82 & 1026b derivative; $\Delta$ purM: $\mathrm{Km}^{r}, \mathrm{Pm}^{r}$ & Propst et al., 2010 \\
\hline RR2683 & Bp82 derivative; $\Delta r m / D: \mathrm{Km}^{r}, \mathrm{Pm}^{\mathrm{r}}$ & This study \\
\hline \multicolumn{3}{|l|}{ B. mallei } \\
\hline ATCC 23344 & Type strain; isolated in 1944 from a human case of glanders & Yabuuchi et al., 1992 \\
\hline \multicolumn{3}{|l|}{ PLASMIDS } \\
\hline \multicolumn{3}{|c|}{ PCR PRIMERS ${ }^{b}$} \\
\hline BprmID-5RPs & 5'-TTGATCACATTCG CTGCAGCACCATC-3' & This study \\
\hline BprmID-3FPs & 5'-GCGATCGATTGCTGCAGGCACGGCCCA-3' & This study \\
\hline BprmID-3RXb & 5'-CATGTCTAGAGACACATTCGGCGAACAATCCATG-3' & This study \\
\hline
\end{tabular}

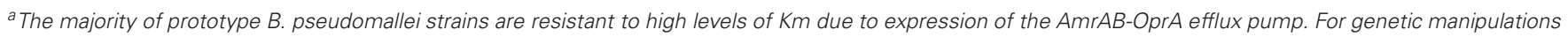
this intrinsic resistance can be overcome using high (>500 $\mathrm{g} / \mathrm{ml}) \mathrm{Km}$ concentrations.

${ }^{b}$ Restriction sites are italicized.

an in-frame deletion in the O-polysaccharide (OPS)-related biosynthetic gene, $r m l D$ (BPSL2683), the rmlD-5FH/rmlD-5RPs and $\mathrm{rmlD}-3 \mathrm{FPs} / \mathrm{rmlD}-3 \mathrm{RXb}$ primer pairs were used to PCR amplify $\sim 600$ bp DNA fragments upstream (rmlD5') and downstream $\left(\mathrm{rmlD}^{\prime}\right)$ of the gene, respectively. The rmlD5' PCR product was digested with HindIII and PstI and cloned into pMo130 digested with the same enzymes resulting in plasmid pMormlD5'. The rmlD3' PCR product was then digested with PstI and XbaI and cloned into pMormlD5' digested with the same enzymes. The resulting plasmid was designated pMo $\Delta \mathrm{rmlD}$ (harboring $r m l D$ with a 354-bp deletion, $\Delta r m l D)$.

To construct the B. pseudomallei OPS mutant strains BP2683 and RR2683, E. coli S17-1 was used to mobilize pMo $\Delta$ rmlD into B. pseudomallei DD503 or Bp82 via conjugative mating essentially as previously described (DeShazer et al., 1997; Burtnick et al., 2011). Briefly, overnight cultures of S17-1 (pMo $\Delta \mathrm{rmlD}$ ) and DD503 or Bp82 were pelleted by centrifugation, resuspended together in $100 \mu \mathrm{l}$ of $10 \mathrm{mM} \mathrm{MgSO}_{4}$, spotted onto LB agar plates and incubated for $18 \mathrm{~h}$ at $37^{\circ} \mathrm{C}$. To select for transconjugants, mating mixtures were plated onto $\mathrm{LB}-\mathrm{Km}-\mathrm{Pm}$ agar and incubated at $37^{\circ} \mathrm{C}$ for $48 \mathrm{~h}$. To select for sucrose resistant colonies, individual transconjugants were inoculated into yeast-tryptone (YT) broth, incubated at $37^{\circ} \mathrm{C}$ for $4-5 \mathrm{~h}$, and then plated onto YT agar containing 15\% sucrose (Hamad et al., 2009). Following incubation at $37^{\circ} \mathrm{C}$ for $48 \mathrm{~h}$, sucrose resistant colonies were screened for loss of the $\mathrm{Km}$ resistance marker by replica plating onto LB and $\mathrm{LB}-\mathrm{Km}$. The resolved co-integrates were screened for the presence of the mutant allele $(\Delta r m l D)$ by PCR.

\section{CPS PURIFICATION}

LBL broth $(4 \times 600 \mathrm{ml}$ in $2 \mathrm{~L}$ baffled Erlenmeyer flasks $)$ was inoculated with B. pseudomallei BP2683 or RR2683 and incubated overnight at $37^{\circ} \mathrm{C}$ with vigorous shaking. Cell pellets were obtained by centrifugation $(10 \mathrm{~min}$ at $8000 \times \mathrm{g})$ and extracted using a modified hot aqueous-phenol procedure (Perry et al., 1995). Following extraction, the resulting phenol and aqueous phases were combined and dialyzed against distilled water to remove the phenol. The dialysates were then clarified by centrifugation $(20 \mathrm{~min}$ at $10,000 \times g)$ and the supernatants concentrated by lyophilization. The crude CPS preparations were solubilized at $20 \mathrm{mg} / \mathrm{ml}$ in RD buffer [10 mM Tris- $\mathrm{HCl}$ ( $\mathrm{pH} 7.5$ ), $1 \mathrm{mM} \mathrm{MgCl} 2,1 \mathrm{mM} \mathrm{CaCl} 2,50 \mu \mathrm{g} / \mathrm{ml} \mathrm{RNase} A$ and $50 \mu \mathrm{g} / \mathrm{ml}$ DNase I] and incubated for $3 \mathrm{~h}$ with gentle shaking at $37^{\circ} \mathrm{C}$. Proteinase $\mathrm{K}$ was then added to a final concentration of $50 \mu \mathrm{g} / \mathrm{ml}$ and the samples were incubated for an additional $3 \mathrm{~h}$ at $60^{\circ} \mathrm{C}$ after which the enzymatic digests were clarified by centrifugation $(20 \mathrm{~min}$ at $10,000 \times g)$. CPS was then isolated from the supernatants as precipitated gels following successive rounds of ultracentrifugation $(3 \times 2 \mathrm{~h}$ at $100,000 \times g$ with the pellets being resuspended in ultrapure water between spins). After the final spin, the gel-like pellets were resuspended in ultrapure water and lyophilized.

To remove the rough LPS contaminants from the CPS preparations, crude samples were solubilized at $5 \mathrm{mg} / \mathrm{ml}$ in $2 \%$ acetic acid and incubated for $2 \mathrm{~h}$ at $100^{\circ} \mathrm{C}$. The hydrolyzed samples were cooled to room temperature and clarified via centrifugation $(20 \mathrm{~min}$ at $10,000 \times g)$ following which the supernatants were carefully removed and lyophilized to concentrate. The lyophilized 
samples were then solubilized at $20 \mathrm{mg} / \mathrm{ml}$ in $100 \mathrm{mM}$ phosphate buffered saline ( $\mathrm{pH} 7.4$; PBS) and clarified using $0.45 \mu \mathrm{m}$ syringe filters. The samples were loaded onto Sephadex G-50 columns $(40 \times 2.6 \mathrm{~cm})$ equilibrated with PBS and eluted with the same buffer. Fractions $(5 \mathrm{ml})$ were collected and assayed for carbohydrate using the phenol-sulfuric acid method (Dubois et al., 1956). Carbohydrate positive fractions eluting near the column void volumes $(\sim 70 \mathrm{ml})$ were pooled, extensively dialyzed against distilled water and lyophilized. Protein and nucleic acid contamination of the resulting CPS preparations were estimated by BCA assay (Pierce) and $\mathrm{A}_{260 / 280}$ measurements, respectively.

\section{NMR SPECTROMETRY}

Column purified CPS was deuterium exchanged by dissolving in $\mathrm{D}_{2} \mathrm{O}$ followed by lyophilization. Samples were then dissolved in $\mathrm{D}_{2} \mathrm{O}$ containing a trace amount of acetone and ${ }^{1} \mathrm{H}$ and ${ }^{13} \mathrm{C}$ NMR spectra were obtained using a Varian Inova-500 $\mathrm{MHz}$ spectrometer at $50^{\circ} \mathrm{C}$ using standard pulse sequences. ${ }^{1} \mathrm{H}$ and ${ }^{13} \mathrm{C}$ chemical shifts were measured relative to the internal acetone reference $\left(\delta_{\mathrm{H}}=2.218 \mathrm{ppm} ; \delta_{\mathrm{C}}=33.0 \mathrm{ppm}\right)$ (Wishart et al., 1995).

\section{GLYCOCONJUGATE SYNTHESIS}

Glycoconjugates were synthesized using established methodologies (Brett and Woods, 1996; Jennings and Lugowski, 1981; Conlan et al., 2002). Briefly, purified CPS was solubilized at $5 \mathrm{mg} / \mathrm{ml}$ in PBS and added to a small amber vial. To each $\mathrm{ml}$ of the solution was added $6 \mathrm{mg}(\sim 30 \mathrm{mM})$ of sodium metaperiodate $\left(\mathrm{NaIO}_{4} ;\right.$ Pierce). Once the crystals had dissolved by gentle agitation, the reaction mixture was gently stirred at room temperature for $40 \mathrm{~min}$. To remove any excess oxidizing agent, the reaction mixture was applied to a Zeba Desalt Spin Column (Pierce) equilibrated with PBS and the eluate collected. To facilitate conjugation of the CPS to cationized bovine serum albumin (cBSA; Pierce), the activated CPS was added to small amber vials. To each $\mathrm{ml}$ of the CPS solutions was added either $0.5,1$, or $2 \mathrm{ml}$ of the carrier protein $(5 \mathrm{mg} / \mathrm{ml}$ in PBS). Following mixing by gentle agitation, $10 \mu \mathrm{l}$ aliquots of a sodium cyanoborohydride stock ( $1 \mathrm{M} \mathrm{NaBH} 3 \mathrm{CN}$ in $10 \mathrm{mM} \mathrm{NaOH}$ ) were added to each $\mathrm{ml}$ of the conjugation mixtures and the reactions were gently stirred at room temperature for $4 \mathrm{~d}$. Following this, $10 \mu \mathrm{l}$ aliquots of a sodium borohydride stock $\left(1 \mathrm{M} \mathrm{NaBH}_{4}\right.$ in $10 \mathrm{mM}$ $\mathrm{NaOH}$ ) were added to each $\mathrm{ml}$ of the conjugation mixtures and the reactions were stirred for $40 \mathrm{~min}$. The conjugate reactions were then brought to $5 \mathrm{ml}$ with ultrapure water, dialyzed against distilled water and then lyophilized. The resulting preparations were resuspended in ultrapure water as $1 \mathrm{mg} / \mathrm{ml}$ stocks and stored at $-20^{\circ} \mathrm{C}$ until required for use. BCA assays were used to quantitate the protein concentrations of the glycoconjugate stocks.

\section{ANTIBODY PRODUCTION}

Standard immunization protocols were used at Cocalico Biologicals, Inc. to generate mouse immune serum samples. Briefly, 6-8 week old female BALB/c mice were immunized subcutaneously on days $0,14,21$, and 49 with $10 \mu \mathrm{g}$ of the CPS2B1 glycoconjugate formulated using TiterMax as an adjuvant. Unconjugated CPS and cBSA antigens served as controls. Terminal bleeds were conducted 7 days after the last immunization. All procedures involving the mice were performed according to protocols approved by the Cocalico Biologicals, Inc. Animal Care and Use Committee.

\section{SDS-PAGE AND WESTERN IMMUNOBLOTTING}

Glycoconjugate samples were solubilized in 1X SDS-PAGE sample buffer and heated to $100^{\circ} \mathrm{C}$ for $5 \mathrm{~min}$ prior to electrophoresis on $12 \%$ Precise gels (Pierce). Proteins were visualized via staining with Coomassie Blue R-250. Whole cell lysates were prepared from B. pseudomallei 1026b and B. mallei ATCC 23344 essentially as previously described (Brett et al., 2011). For immunoblot analyses, treated whole cell lysates or the glycoconjugate samples were separated on $12 \%$ Precise gels and electrophoretically transferred to nitrocellulose membranes. The membranes were blocked with $3 \%$ skim milk in high salt Tris-buffered saline (HS-TBS; $20 \mathrm{mM}$ Tris, $500 \mathrm{mM} \mathrm{NaCl}, \mathrm{pH} 7.5$ ) for $60 \mathrm{~min}$ at room temperature and then incubated overnight at $4^{\circ} \mathrm{C}$ with $1 / 1000$ dilutions of pooled anti-CPS2B1 immune serum or the CPS-specific mAb, 3C5 (Nuti et al., 2011). To facilitate detection, the membranes were incubated for $1 \mathrm{~h}$ at room temperature with $1 / 5000$ dilutions of an anti-mouse $\operatorname{IgG}$ horse radish peroxidase conjugate (SouthernBiotech). The blots were then visualized using HRP Color Development Reagent (Bio-Rad) or Pierce ECL Western Blotting Substrate (Pierce).

\section{QUANTITATION OF IMMUNOGLOBULIN TITERS BY ELISA}

Ninenty-six-well Maxisorp plates (Nunc) were coated overnight at $4^{\circ} \mathrm{C}$ with purified CPS $(10 \mu \mathrm{g} / \mathrm{ml})$ solubilized in carbonate buffer ( $\mathrm{pH}$ 9.6). The plates were blocked at room temperature for 30 min with StartingBlock T20 (TBS) Blocking Buffer (Pierce) and then incubated for $2 \mathrm{~h}$ at $37^{\circ} \mathrm{C}$ with the mouse serum samples serially diluted in Tris-buffered saline $+0.05 \%$ Tween 20 (TBS-T; pH 7.5) + 10\% StartingBlock T20. To facilitate detection, the plates were incubated for $1 \mathrm{~h}$ at $37^{\circ} \mathrm{C}$ with $1 / 2000$ dilutions of an anti-mouse IgG horse radish peroxidase conjugate (SouthernBiotech). The plates were then developed with TMB substrate (KPL) and read at $620 \mathrm{~nm}$. The reciprocals of the highest dilutions exhibiting ODs of $>0.150$ were used to determine the endpoint titers for the individual mice. The data was plotted and analyzed using GraphPad Prism 5 (GraphPad Software Inc.). Statistical differences between geometric mean IgG titers was assessed by Mann-Whitney rank sum analysis with the significance set at $P<0.05$.

\section{CELL CULTURE AND OPSONOPHAGOCYTOSIS ASSAYS}

The murine macrophage cell line RAW 264.7 (ATCC TIB-71) was maintained in Dulbecco's modified Eagle's medium supplemented with $10 \%(\mathrm{v} / \mathrm{v})$ heat inactivated (HI) fetal bovine serum (DMEM-10; Invitrogen) and a standard mixture of antibiotics $\left(100 \mathrm{U} \mathrm{ml}^{-1}\right.$ penicillin, $100 \mu \mathrm{g} \mathrm{ml}^{-1}$ streptomycin and $250 \mu \mathrm{g}$ $\mathrm{ml}^{-1}$ amphotericin B; Sigma) at $37^{\circ} \mathrm{C}$ under an atmosphere of $5 \% \mathrm{CO}_{2}$. Opsonophagocytosis assays were based upon previously described methods (Simon et al., 2011; Tennant et al., 2011). Briefly, RAW 264.7 cells resuspended in DMEM-10 were 
transferred into 24-well tissue culture plates at a density of $\sim 1 \times 10^{6}$ cells/well and incubated overnight. B. mallei cultures grown to early-log phase were pelleted, resuspended at a density of $\sim 10^{6} \mathrm{cfu} / \mathrm{ml}$ in DMEM or DMEM containing $0.2 \%$ cBSA or CPS2B1 mouse immune serum (pooled and HI for $30 \mathrm{~min}$ at $56^{\circ} \mathrm{C}$ ) and then incubated at $37^{\circ} \mathrm{C}$ for $1 \mathrm{~h}$. RAW 264.7 monolayers were washed twice with Hanks' Balanced Salts Solution (HBSS; Invitrogen) prior to the addition of the opsonized bacterial suspensions. The monolayers were incubated with the bacteria at $37^{\circ} \mathrm{C}$ under an atmosphere of $5 \% \mathrm{CO}_{2}$ for $1 \mathrm{~h}$ and then washed twice with HBSS to remove extracellular bacteria. Infected RAW 264.7 cells were incubated in fresh DMEM-10 containing $250 \mu \mathrm{g} / \mathrm{ml} \mathrm{km}$ to suppress the growth of residual extracellular bacteria. At $3 \mathrm{~h}$ post-infection, monolayers were washed twice with HBSS, lysed with $0.2 \%(\mathrm{v} / \mathrm{v})$ Triton X-100 (Sigma) and serial dilutions of the lysates were plated onto LB agar supplemented with $4 \%$ glycerol and incubated at $37^{\circ} \mathrm{C}$ for $48 \mathrm{~h}$. Plate counts were used to enumerate bacterial loads. The data was plotted and analyzed using GraphPad Prism 5. Statistical differences were assessed by $t$-test with the significance set at $P<0.05$.

\section{RESULTS AND DISCUSSION \\ PURIFICATION AND CHARACTERIZATION OF B. pseudomallei CPS ANTIGENS}

Previous studies by Perry et al. (1995) have shown that a modified enzyme hot aqueous-phenol procedure can be used to isolate OPS and CPS antigens from wild type strains of B. pseudomallei. Since both of these high molecular weight species partition into the phenol phase during the extraction step, separation of these antigens from one another during downstream purification can be challenging. Fortunately, studies have demonstrated that highly purified preparations of CPS can be obtained from naturally occurring isolates of $B$. pseudomallei expressing rough LPS antigens (Perry et al., 1995). Based upon these observations, we used allelic exchange mutagenesis to construct the OPS-deficient mutant, B. pseudomallei BP2683, to help facilitate the development of our CPS-based glycoconjugates (Heiss et al., 2012). Utilizing this strain, we found that we could obtain highly purified preparations of CPS from B. pseudomallei since lower molecular weight contaminants (e.g., rough LPS) rather than higher molecular weight contaminants (e.g., smooth LPS) could be easily separated from the homopolymer by size exclusion chromatography (Figure 1). Recently, we have also been successful in isolating CPS from B. pseudomallei RR2683, an OPS-deficient derivative of the select agent excluded strain Bp82 (Propst et al., 2010). By using this mutant strain, we now have the ability to more safely and cost-effectively purify CPS from B. pseudomalle $i$ without the requirement for BSL-3 containment which should help to accelerate the pace of our research.

Using the purification strategy outlined in the "Materials and Methods" section, we routinely obtain 10-15 mg of CPS per liter of BP2683 or RR2683 culture with the resulting antigen preparations being devoid of any detectable protein or nucleic acid contamination as determined by BCA assay or UV spectroscopy. To assess the structural integrity and homogeneity of the CPS preparations, samples are also analyzed by

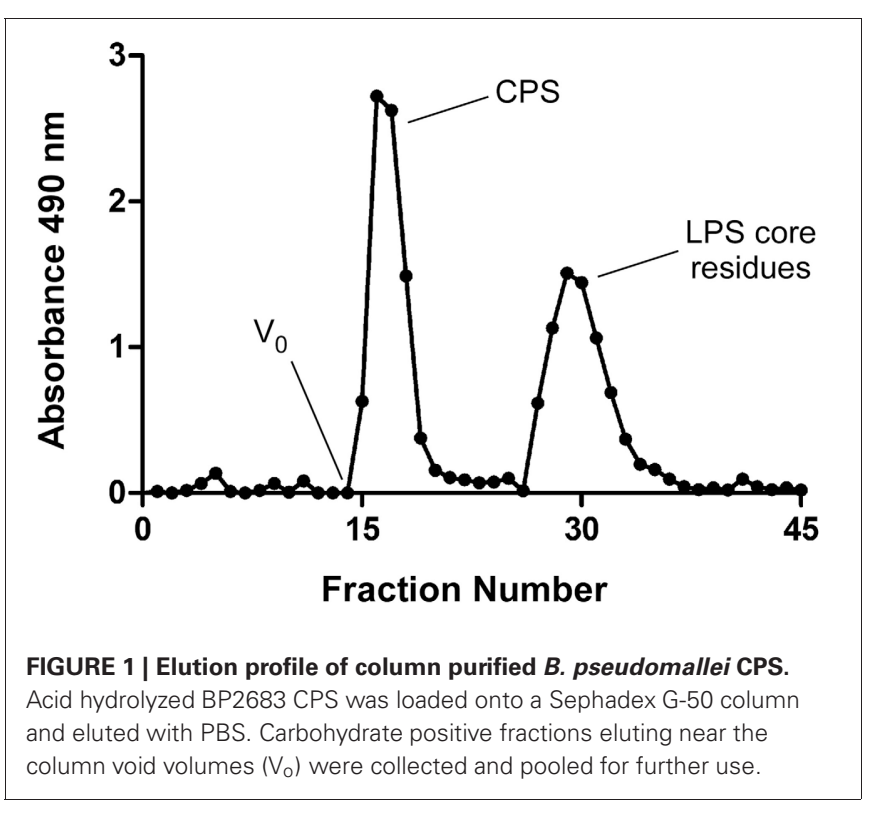

NMR spectrometry. Using this approach, ${ }^{1} \mathrm{H}$ and ${ }^{13} \mathrm{C}$ NMR analyses confirm that the main component of these preparations is the desired 2-O-acetylated 6-deoxy-heptan homopolymer (Figures 2A,B). In addition, such analyses indicate that the preparations are $\sim 95 \%$ pure with the remainder of the samples consisting of the unique mannan CPS recently discovered by Heiss et al. (2012).

\section{CONJUGATION OF CPS TO CARRIER PROTEINS}

To facilitate the coupling of B. pseudomallei CPS to protein carriers, we have found that $\mathrm{NaIO}_{4}$ is well suited for chemically activating the polysaccharide. The decision to use $\mathrm{NaIO}_{4}$ was based upon several considerations including (1) the absence of amines or carboxylates in the antigen that would favor conjugation via other methods, (2) the relative safety of the compound over alternatives such as cyanogen bromide, (3) the use of reaction conditions to minimize the risk of reducing alkalisensitive $O$-acetyl modifications, (4) the desire to construct neoglycoconjugates rather than cross-linked network conjugates (Jones, 2005). Using the approach outlined in Figure 3, reactive aldehydes incorporated into the reducing/non-reducing termini of $B$. pseudomallei CPS facilitate the conjugation of the antigen to carrier proteins via reductive amination. To reduce the Schiff bases formed during the coupling reactions, $\mathrm{NaBH}_{3} \mathrm{CN}$ was chosen as the primary reducing reagent because, unlike $\mathrm{NaBH}_{4}$, it rapidly modifies Schiff bases but not aldehydes. Once the CPS moieties are coupled to carrier proteins, $\mathrm{NaBH}_{4}$ is then added to quench any residual aldehydes in the reaction mixtures.

The CPS-based glycoconjugates synthesized in this study were constructed using cBSA as the protein carrier. The decision to use cBSA for this purpose was based on several considerations, including the fact that it is (1) a well characterized immunogen, (2) commercially available, and (3) affordable. To facilitate our studies, glycoconjugates were synthesized by reacting various ratios of chemically activated CPS and cBSA with one another 
A
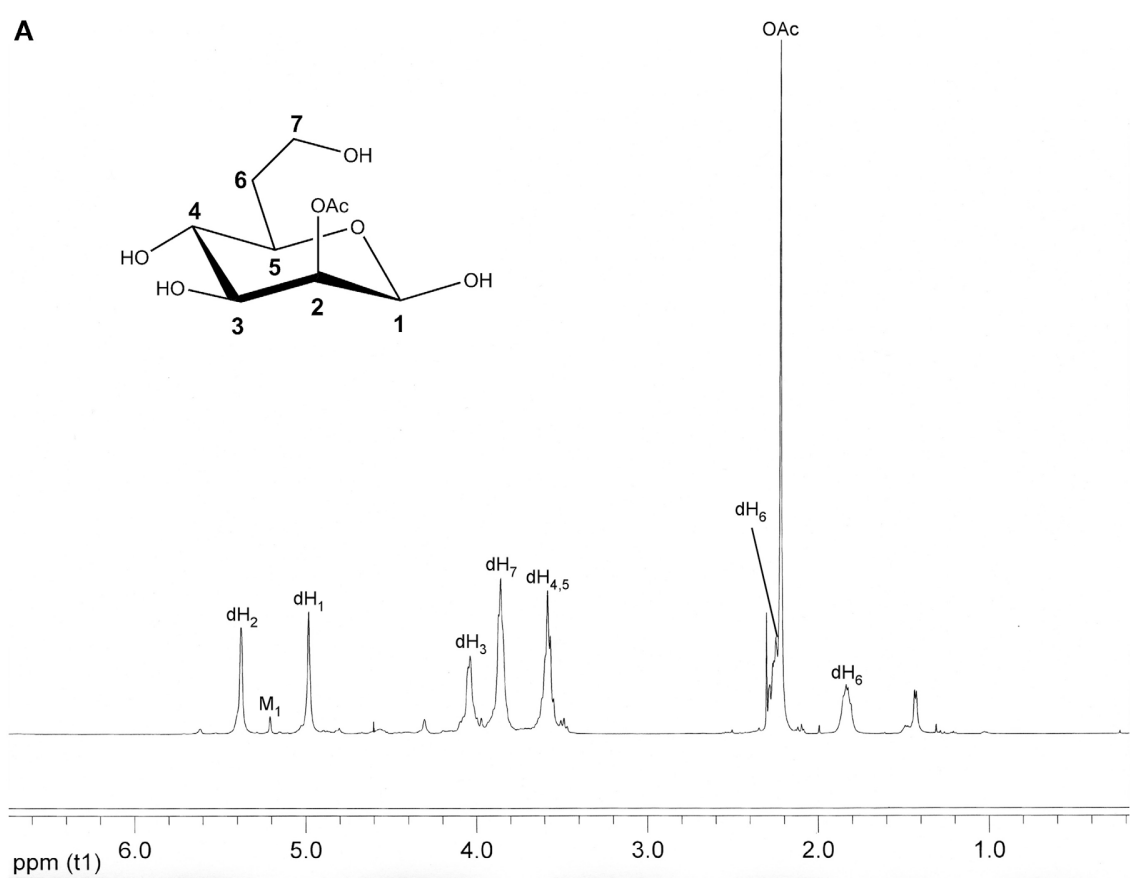

B

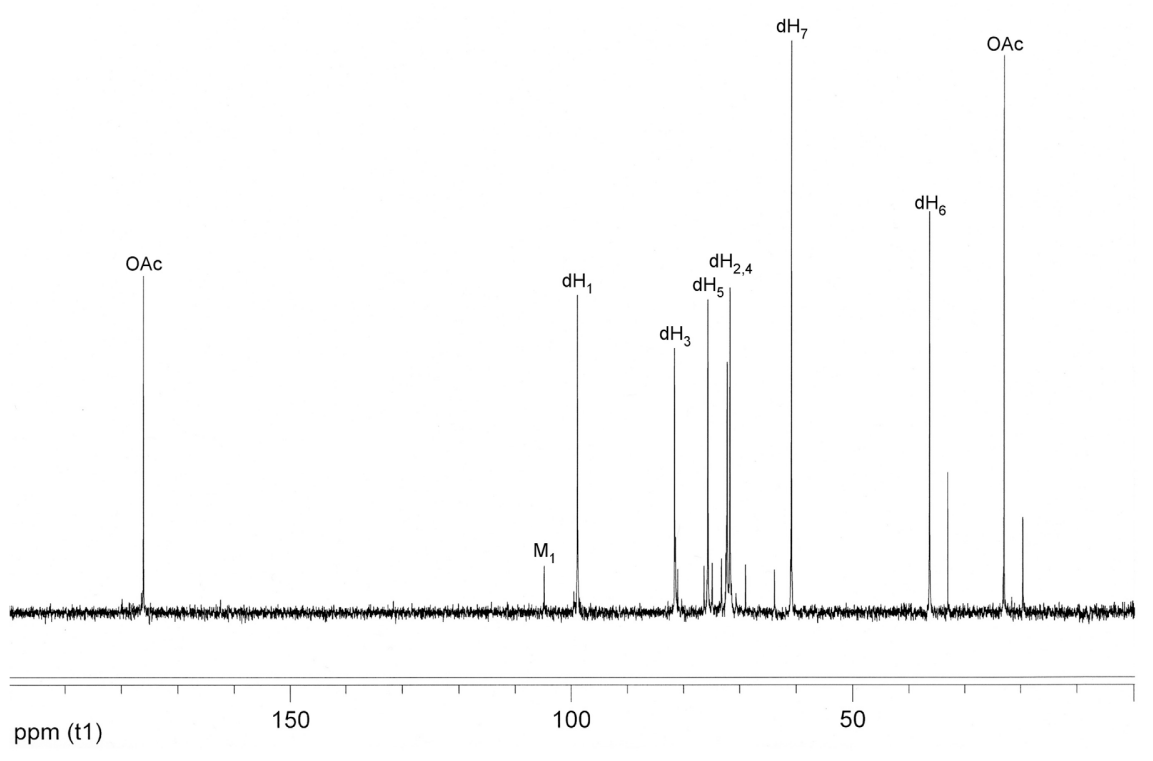

FIGURE 2 | Structural analysis of B. pseudomallei CPS. (A) ${ }^{1} \mathrm{H}$ NMR and (B) ${ }^{13} \mathrm{C}$ NMR spectra were obtained for column purified BP2683 CPS using a Varian Inova-500 MHz spectrometer. For reference purposes, the chemical structure of the monosaccharide making up the CPS homopolymer is inset in panel $\mathbf{A}$. dH, 6-deoxy-heptose; $\mathrm{M}$, mannose; OAc, O-acetyl. (e.g., 2:1, 1:1, and 1:2 ratios of CPS:cBSA). Following conjugation of the antigens, the samples were examined by SDS-PAGE. Results of these analyses indicated that in all instances, the CPS had covalently linked to the protein carrier as demonstrated by the shift in molecular weight of the $\mathrm{BSA}$ relative to the unconjugated control (Figure 4A). In addition, Western immunobloting confirmed that the structural integrity/antigenicity of the CPS moieties remained intact following chemical activation and linkage to the protein carrier based upon their reactivity with the 3C5 mAb (Figure 4B). Furthermore, studies demonstrated that by varying initial carbohydrate to protein ratios, we could influence the molecular weights of the resulting glycoconjugates. 


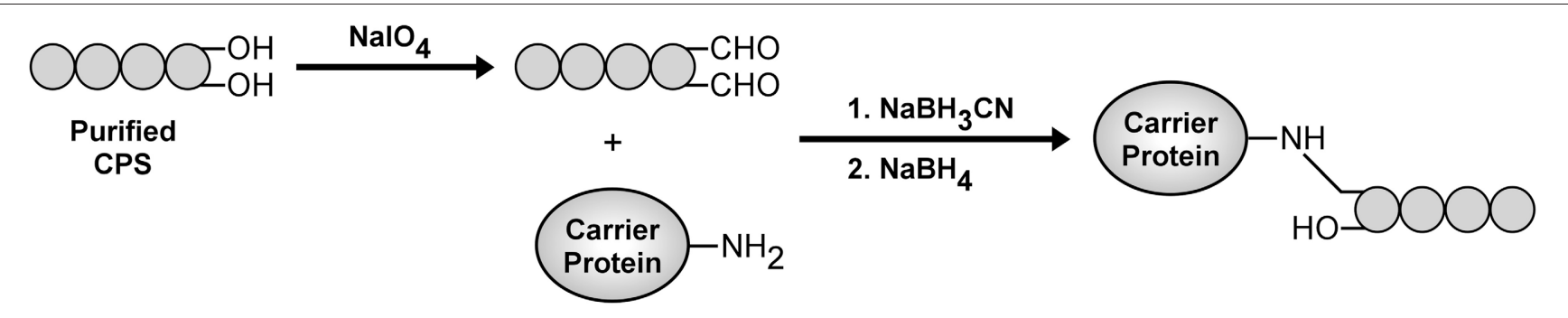

FIGURE 3 | Generalized scheme for the conjugation of activated B. pseudomallei CPS to carrier proteins.

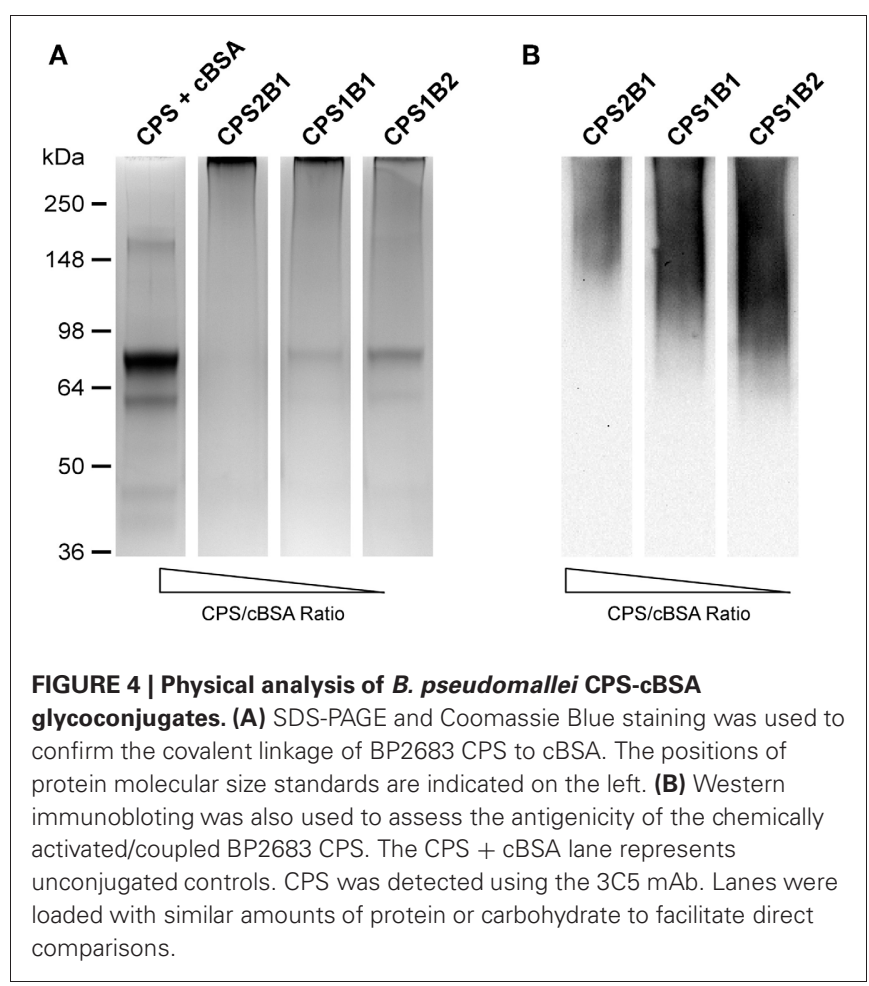

IMMUNE RESPONSES AGAINST CPS-BASED GLYCOCONJUGATES

Efforts to overcome the poor immunogenicity of many polysaccharides has led to the development of conjugate vaccines (Lockhart, 2003). Covalent linkage of polysaccharides to carrier proteins enables them to stimulate humoral immune responses characteristic of T cell-dependent antigens. By recruiting Th cell involvement, immunological memory is evoked, isotype switching occurs and complement-activating/opsonizing antibody isotypes are generated. The avidities of the antibodies elicited by glycoconjugates are also much higher than those produced by polysaccharides alone (Kuberan and Linhardt, 2000; Lesinski and Westerink, 2001; Weintraub, 2003).

To examine the immunogenic potential of the glycoconjugates synthesized in this study, mice were immunized with the CPS2B1 construct (37\% protein on a $\mathrm{w} / \mathrm{w}$ basis) as well as unconjugated controls. Analysis of the resulting serum samples indicated that mice immunized with the glycoconjugate exhibited significantly higher anti-CPS IgG titers (45-fold) than

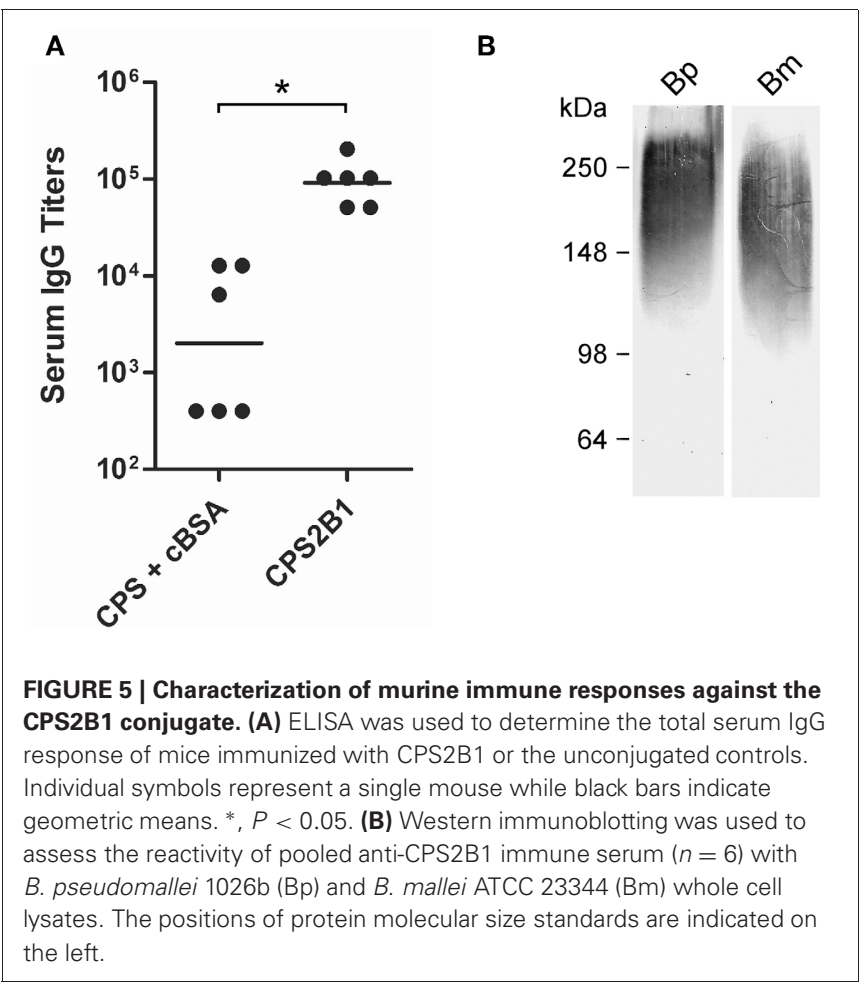

those immunized with the unconjugated control (Figure 5A). To further examine the immune response raised against CPS2B1, mouse serum samples were pooled and reacted against proteinase $\mathrm{K}$ treated whole cell lysates of $B$. pseudomallei and $B$. mallei by Western immunoblotting. As anticipated, results demonstrated that the antiserum reacted strongly with CPS antigens expressed by both pathogens (Figure 5B). In addition, the CPS2B1 antiserum was examined for its ability to mediate opsonophagocytic uptake. As shown in Figure 6, pre-incubation of B. mallei with pooled anti-CPS2B1 serum, but not pooled anti-cBSA serum, significantly enhanced bacterial uptake into RAW 264.7 murine macrophages.

\section{CONCLUSIONS}

Melioidosis and glanders are emerging/re-emerging infectious diseases for which no licensed vaccines currently exist. Several recent reports have demonstrated that mAbs specific for the 6-deoxy-heptan CPS expressed by B. pseudomallei and B. mallei 


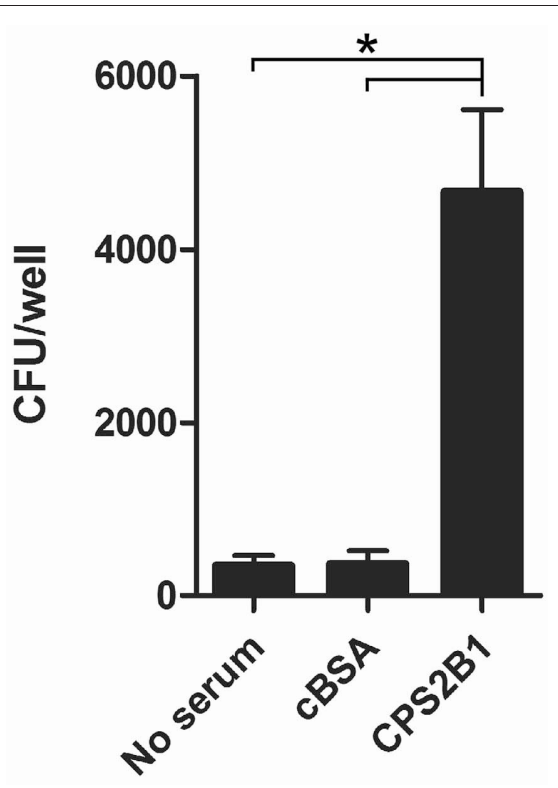

FIGURE 6 | Opsonophagocytic uptake of B. mallei by RAW 264.7 murine macrophages. Bacterial uptake in the presence of DMEM alone (no serum), pooled $\mathrm{HI}$ anti-cBSA immune serum (cBSA; $n=6$ ) or pooled $\mathrm{HI}$ anti-CPS2B1 immune serum (CPS2B1; $n=6$ ) was quantitated at $3 \mathrm{~h}$ post-infection. Values represent the means $\pm \mathrm{SD}$ of three independent experiments. ${ }^{*}, P<0.05$.

are passively protective in animal models of infection (Jones et al., 2002; Nelson et al., 2004; Zhang et al., 2011; AuCoin et al., 2012). Because of this, research in our lab is focused on developing CPSbased vaccines to immunize humans and animals against diseases caused by these bacterial pathogens. In the present study, we have

\section{REFERENCES}

Amemiya, K., Bush, G. V., DeShazer, D., and Waag, D. M. (2002). Nonviable Burkholderia mallei induces a mixed Th1- and Th2-like cytokine response in $\mathrm{BALB} / \mathrm{c}$ mice. Infect. Immun. 70, 2319-2325.

Amemiya, K., Meyers, J. L., Trevino, S. R., Chanh, T. C., Norris, S. L., and Waag, D. M. (2006). Interleukin12 induces a Thl-like response to Burkholderia mallei and limited protection in BALB/c mice. Vaccine 24, 1413-1420.

Atkins, T., Prior, R. G., Mack, K., Russell, P., Nelson, M., Oyston, P. C., Dougan, G., and Titball, R. W. (2002). A mutant of Burkholderia pseudomallei, auxotrophic in the branched chain amino acid biosynthetic pathway, is attenuated and protective in a murine model of melioidosis. Infect. Immun. 70, 5290-5294.
AuCoin, D. P., Reed, D. E., Marlenee, N. L., Bowen, R. A., Thorkildson, P., Judy, B. M., Torres, A. G., and Kozel, T. R. (2012). Polysaccharide specific monoclonal antibodies provide passive protection against intranasal challenge with Burkholderia pseudomallei. PLoS ONE 7:e35386. doi: 10.1371/journal.pone.0035386

Bazaka, K., Crawford, R. J., Nazarenko, E. L., and Ivanova, E. P. (2011). Bacterial extracellular polysaccharides. Adv. Exp. Med. Biol. 715, 213-226.

Bondi, S. K., and Goldberg, J. B. (2008). Strategies toward vaccines against Burkholderia mallei and Burkholderia pseudomallei. Expert Rev. Vaccines 7, 1357-1365.

Brett, P. J., Burtnick, M. N., Heiss, C., Azadi, P., DeShazer, D., Woods, D. E., and Gherardini, F. C. (2011). Burkholderia thailandensis oacA mutants facilitate the expression of Burkholderia mallei-like O

detailed for the first time, methodologies to facilitate the isolation and structural validation of highly purified preparations of CPS from various $B$. pseudomallei 1026b derivatives. In addition, we have described a simple strategy for covalently linking these carbohydrate antigens to carrier proteins. Using these approaches, we have also demonstrated that high titer IgG responses can be raised against the carbohydrate component of the CPS-based glycoconjugates. Based upon these observations, studies are currently underway to assess the protective capacity of our prototype glycoconjugates in animal models of infection.

Because of obvious limitations regarding the use of $\mathrm{cBSA}$ as a carrier for vaccine development, studies are ongoing to explore the use of licensed carriers (e.g., CRM197, CtxB, ExoA etc.) or specific Burkholderia proteins (e.g., LolC, Hcp1, BipD etc.) for this purpose. When doing so, it will be important to evaluate if coupling of the CPS to the different carrier proteins affects their stability and immunogenicity. We anticipate that approaches such as ELISA, circular dichroism spectroscopy and protein NMR spectrometry will be required to assess these types of issues. Additionally, studies are being planned to investigate how differing adjuvants and dosing regimens might influence immune responses raised against our glycoconjugates. Collectively, it is anticipated that such studies will further provide important insights toward the rational design of efficacious melioidosis and glanders vaccine candidates.

\section{ACKNOWLEDGMENTS}

We thank David AuCoin for generously providing the 3C5 mAb. This research was supported in part by the National Institute of Allergy and Infectious Diseases, National Institutes of Health (grant R21AI088418), the Department of Energy-funded Center for Plant and Microbial Complex Carbohydrates (grant DEFG09-93ER-20097) and lab start-up funds from the University of South Alabama.

polysaccharides. Infect. Immun. 79, 961-969.

Brett, P. J., DeShazer, D., and Woods, D. E. (1998). Burkholderia thailandensis sp. nov., a Burkholderia pseudomallei-like species. Int. J. Syst. Bacteriol. 48(Pt 1), 317-320.

Brett, P. J., and Woods, D. E. (1996). Structural and immunological characterization of Burkholderia pseudomallei $\mathrm{O}$-polysaccharide-flagellin protein conjugates. Infect. Immun. 64, 2824-2828.

Burtnick, M. N., Brett, P. J., Harding, S. V., Ngugi, S. A., Ribot, W. J., Chantratita, N., Scorpio, A., Milne, T. S., Dean, R. E., Fritz, D. L., Peacock, S. J., Prior, J. L., Atkins, T. P., and Deshazer, D. (2011). The cluster 1 type VI secretion system is a major virulence determinant in Burkholderia pseudomallei. Infect. Immun. 79, 1512-1525.

Conlan, J. W., Shen, H., Webb, A., and Perry, M. B. (2002). Mice vaccinated with the O-antigen of Francisella tularensis LVS lipopolysaccharide conjugated to bovine serum albumin develop varying degrees of protective immunity against systemic or aerosol challenge with virulent type A and type B strains of the pathogen. Vaccine 20, 3465-3471.

DeShazer, D., Brett, P. J., Carlyon, R., and Woods, D. E. (1997). Mutagenesis of Burkholderia pseudomalle $i$ with Tn5-OT182, isolation of motility mutants and molecular characterization of the flagellin structural gene. J. Bacteriol. 179, 2116-2125.

DeShazer, D., Waag, D. M., Fritz, D. L., and Woods, D. E. (2001). Identification of a Burkholderia mallei polysaccharide gene cluster by subtractive hybridization and demonstration that the encoded capsule is an essential virulence determinant. Microb. Pathog. 30, 253-269. 
Dubois, M., Gilles, K., Hamilton, J. K., Rebers, P. A., and Smith, F. (1956). Colormiteric method for determination of sugars and related substances. Anal. Chem. 28, 350-356.

Galyov, E. E., Brett, P. J., and Deshazer, D. (2010). Molecular insights into Burkholderia pseudomallei and Burkholderia mallei pathogenesis. Annu. Rev. Microbiol. 64, 495-517.

Hamad, M. A., Zajdowicz, S. L., Holmes, R. K., and Voskuil, M. I. (2009). An allelic exchange system for compliant genetic manipulation of the select agents Burkholderia pseudomallei and Burkholderia mallei. Gene 430, 123-131.

Heiss, C., Burtnick, M. N., Wang, Z., Azadi, P., and Brett, P. J. (2012). Structural analysis of capsular polysaccharides expressed by Burkholderia mallei and Burkholderia pseudomallei. Carbohydr. Res. 349, 90-94.

Howe, C., and Miller, W. R. (1947). Human glanders: report of six cases. Ann. Intern. Med. 26, 93-115.

Jennings, H. J., and Lugowski, C. (1981). Immunochemistry of groups $\mathrm{A}, \mathrm{B}$, and $\mathrm{C}$ meningococcal polysaccharide-tetanus toxoid conjugates. J. Immunol. 127, 1011-1018.

Jones, C. (2005). Vaccines based on the cell surface carbohydrates of pathogenic bacteria. An. Acad. Bras. Cienc. 77, 293-324.

Jones, S. M., Ellis, J. F., Russell, P., Griffin, K. F., and Oyston, P. C. (2002). Passive protection against Burkholderia pseudomallei infection in mice by monoclonal antibodies against capsular polysaccharide, lipopolysaccharide or proteins. J. Med. Microbiol. 51, 1055-1062.

Khan, I., Wieler, L. H., Melzer, F., Elschner, M. C., Muhammad, G., Ali, S., Sprague, L. D., Neubauer, H., and Saqib, M. (2012). Glanders in animals: a review on epidemiology, clinical presentation, diagnosis and countermeasures. Transbound. Emerg. Dis. doi: 10.1111/j.18651682.2012.01342.x. [Epub ahead of print].

Kuberan, B., and Linhardt, R. J. (2000). Carbohydrate based vaccines. Curr. Org. Chem. 4, 653-677.

Lesinski, G. B., and Westerink, M. A. (2001). Vaccines against polysaccharide antigens. Curr. Drug Targets. Infect. Disord. 1, 325-334.

Limmathurotsakul, D., Thammasart, S., Warrasuth, N., Thapanagulsak, P., Jatapai, A., Pengreungrojanachai, V., Anun, S., Joraka, W., Thongkamkoon, P., Saiyen, P., Wongratanacheewin, S., Day,
N. P., and Peacock, S. J. (2012). Melioidosis in animals, Thailand, 2006-2010. Emerg. Infect. Dis. 18, 325-327.

Lockhart, S. (2003). Conjugate vaccines. Expert Rev. Vaccines 2, 633-648.

Meumann, E. M., Cheng, A. C., Ward, L., and Currie, B. J. (2012). Clinical features and epidemiology of melioidosis pneumonia: results from a 21-year study and review of the literature. Clin. Infect. Dis. 54, 362-369.

Moore, R. A., DeShazer, D., Reckseidler S., Weissman, A., and Woods, D. E. (1999). Efflux-mediated aminoglycoside and macrolide resistance in Burkholderia pseudomallei. Antimicrob. Agents Chemother. 43, 465-470.

Nelson, M., Prior, J. L., Lever, M. S., Jones, H. E., Atkins, T. P., and Titball, R. W. (2004). Evaluation of lipopolysaccharide and capsular polysaccharide as subunit vaccines against experimental melioidosis. J. Med. Microbiol. 53 1177-1182.

Norris, M. H., Propst, K. L., Kang, Y., Dow, S. W., Schweizer, H. P., and Hoang, T. T. (2011). The Burkholderia pseudomallei $\Delta$ asd mutant exhibits attenuated intracellular infectivity and imparts protection against acute inhalation melioidosis in mice. Infect. Immun. 79, 4010-4018.

Nuti, D. E., Crump, R. B., Dwi Handayani, F., Chantratita, N., Peacock, S. J., Bowen, R., Felgner, P. L., Huw Davies, D., Wu, T., Lyons, C. R., Brett, P. J., Burtnick, M. N., Kozel, T. R., and Aucoin, D. P. (2011). Identification of circulating bacterial antigens by in vivo microbial antigen discovery. MBio. pii, e00136-11.

Peacock, S. J., Limmathurotsakul, D., Lubell, Y., Koh, G. C., White, L. J., Day, N. P., and Titball, R. W. (2012). Melioidosis vaccines: a systematic review and appraisal of the potential to exploit biodefense vaccines for public health purposes. PLoS Negl. Trop. Dis. 6:e1488. doi: 10.1371/journal.pntd.0001488

Perry, M. B., Maclean, L. L., Schollaardt, T., Bryan, L. E., and Ho, M. (1995). Structural characterization of the lipopolysaccharide $\mathrm{O}$ antigens of Burkholderia pseudomallei. Infect. Immun. 63 3348-3352.

Propst, K. L., Mima, T., Choi, K. H., Dow, S. W., and Schweizer, H. P. (2010). A Burkholderia pseudomallei $\triangle$ purM mutant is avirulent in immunocompetent and immunodeficient animals: candidate strain for exclusion from select-agent lists. Infect. Immun. 78 3136-3143.

Reckseidler, S. L., DeShazer, D., Sokol, P. A., and Woods, D. E. (2001). Detection of bacterial virulence genes by subtractive hybridization: identification of capsular polysaccharide of Burkholderia pseudomallei as a major virulence determinant. Infect. Immun. 69 34-44.

Reckseidler-Zenteno, S. L., Devinney, R., and Woods, D. E. (2005). The capsular polysaccharide of Burkholderia pseudomallei contributes to survival in serum by reducing complement factor $\mathrm{C} 3 \mathrm{~b}$ deposition. Infect. Immun. 73, 1106-1115.

Redfearn, M. S., Palleroni, N. J., and Stanier, R. Y. (1966). A comparative study of Pseudomonas pseudomallei and Bacillus mallei. J. Gen. Microbiol. 43, 293-313.

Rotz, L. D., Khan, A. S., Lillibridge, S. R., Ostroff, S. M., and Hughes, J. M. (2002). Public health assessment of potential biological terrorism agents. Emerg. Infect. Dis. 8, 225-230.

Sarkar-Tyson, M., Smither, S. J., Harding, S. V., Atkins, T. P., and Titball, R. W. (2009). Protective efficacy of heat-inactivated $B$. thailandensis, B. mallei or B. pseudomallei against experimental melioidosis and glanders. Vaccine 27, 4447-4451.

Sarkar-Tyson, M., and Titball, R. W (2010). Progress toward development of vaccines against melioidosis: a review. Clin. Ther. 32, 1437-1445.

Sim, B. M., Chantratita, N., Ooi, W. F., Nandi, T., Tewhey, R., Wuthiekanun, V., Thaipadungpanit, J., Tumapa, S., Ariyaratne, P., Sung, W. K., Sem, X. H., Chua, H. H., Ramnarayanan, K., Lin, C. H., Liu, Y., Feil, E. J., Glass, M. B., Tan, G., Peacock, S. J., and Tan, P. (2010). Genomic acquisition of a capsular polysaccharide virulence cluster by non-pathogenic Burkholderia isolates. Genome Biol. 11, R89.

Simon, R., Priefer, U., and Puhler, A. (1983). A broad host range mobilization system for in vivo genetic engineering: transposon mutagenesis in Gram negative bacteria. Biotechnology 1, 784-791.

Simon, R., Tennant, S. M., Wang, J. Y., Schmidlein, P. J., Lees, A., Ernst, R. K., Pasetti, M. F., Galen, J. E., and Levine, M. M. (2011). Salmonella enterica serovar enteritidis core $\mathrm{O}$ polysaccharide conjugated to $\mathrm{H}$ :g,m flagellin as a candidate vaccine for protection against invasive infection with S. enteritidis. Infect. Immun. 79, 4240-4249.

Stevens, M. P., Haque, A., Atkins, T., Hill, J., Wood, M. W., Easton, A. Nelson, M., Underwood-Fowler, C., Titball, R. W., Bancroft, G. J., and Galyov, E. E. (2004). Attenuated virulence and protective efficacy of a Burkholderia pseudomallei bsa type III secretion mutant in murine models of melioidosis. Microbiology 150, 2669-2676.

Tennant, S. M., Wang, J. Y., Galen, J. E., Simon, R., Pasetti, M. F., Gat, O., and Levine, M. M. (2011). Engineering and preclinical evaluation of attenuated nontyphoidal Salmonella strains serving as live oral vaccines and as reagent strains. Infect. Immun. 79, 4175-4185.

Ulrich, R. L., Amemiya, K., Waag, D. M., Roy, C. J., and DeShazer, D. (2005). Aerogenic vaccination with a Burkholderia mallei auxotroph protects against aerosolinitiated glanders in mice. Vaccine 23, 1986-1992.

Voskuhl, G. W., Cornea, P., Bronze, M. S., and Greenfield, R. A. (2003). Other bacterial diseases as a potential consequence of bioterrorism: Q fever, brucellosis, glanders, and melioidosis. J. Okla. State Med. Assoc. 96, 214-217.

Weintraub, A. (2003). Immunology of bacterial polysaccharide antigens. Carbohydr. Res. 338, 2539-2547.

White, N. J. (2003). Melioidosis. Lancet 361, 1715-1722.

Whitlock, G. C., Estes, D. M., and Torres, A. G. (2007). Glanders: off to the races with Burkholderia mallei. FEMS Microbiol. Lett. 277, 115-122.

Whitlock, G. C., Lukaszewski, R. A. Judy, B. M., Paessler, S., Torres, A. G., and Estes, D. M. (2008). Host immunity in the protective response to vaccination with heatkilled Burkholderia mallei. BMC Immunol. 9, 55.

Wiersinga, W. J., van der Poll, T., White, N. J., Day, N. P., and Peacock, S. J. (2006). Melioidosis: insights into the pathogenicity of Burkholderia pseudomallei. Nat. Rev. Microbiol. 4, 272-282.

Wishart, D. S., Bigam, C. G., Yao, J., Abildgaard, F., Dyson, H. J., Oldfield, E., Markley, J. L., and Sykes, B. D. (1995). 1H, 13C and $15 \mathrm{~N}$ chemical shift referencing in biomolecular NMR. J. Biomol. NMR 6, 135-140

Yabuuchi, E., Kosako, Y., Oyaizu, H. Yano, I., Hotta, H., Hashimoto, Y., Ezaki, T., and Arakawa, M. (1992). 
Proposal of Burkholderia gen. nov. and transfer of seven species of the genus Pseudomonas homology group II to the new genus, with the type species Burkholderia cepacia (Palleroni and Holmes 1981) comb. nov. Microbiol. Immunol. 36, 1251-1275.

Zhang, S., Feng, S. H., Li, B., Kim, H. Y., Rodriguez, J., Tsai, S., and Lo, S. C. (2011). In Vitro and In Vivo studies of monoclonal antibodies with prominent bactericidal activity against Burkholderia pseudomallei and Burkholderia mallei. Clin. Vaccine Immunol. 18, 825-834.

Zou, N., Tsai, S., Feng, S. H., Newsome, T., Kim, H. Y., Li, B., Zhang, S., and Lo, S. C. (2008). Relationship between antigenicity and pathogenicity for Burkholderia pseudomallei and Burkholderia mallei revealed by a large panel of mouse MAbs. Hybridoma (Larchmt) 27, 231-240.
Conflict of Interest Statement: The authors declare that the research was conducted in the absence of any commercial or financial relationships that could be construed as a potential conflict of interest.

Received: 25 June 2012; accepted: 28 July 2012; published online: 15 August 2012. Citation: Burtnick MN, Heiss C, Roberts RA, Schweizer HP, Azadi $P$ and Brett PJ (2012) Development of capsular polysaccharide-based glycoconjugates for immunization against melioidosis and glanders. Front. Cell. Inf. Microbio. 2:108. doi: 10.3389/fcimb.2012.00108 Copyright (C) 2012 Burtnick, Heiss, Roberts, Schweizer, Azadi and Brett. This is an open-access article distributed under the terms of the Creative Commons Attribution License, which permits use, distribution and reproduction in other forums, provided the original authors and source are credited and subject to any copyright notices concerning any third-party graphics etc. 